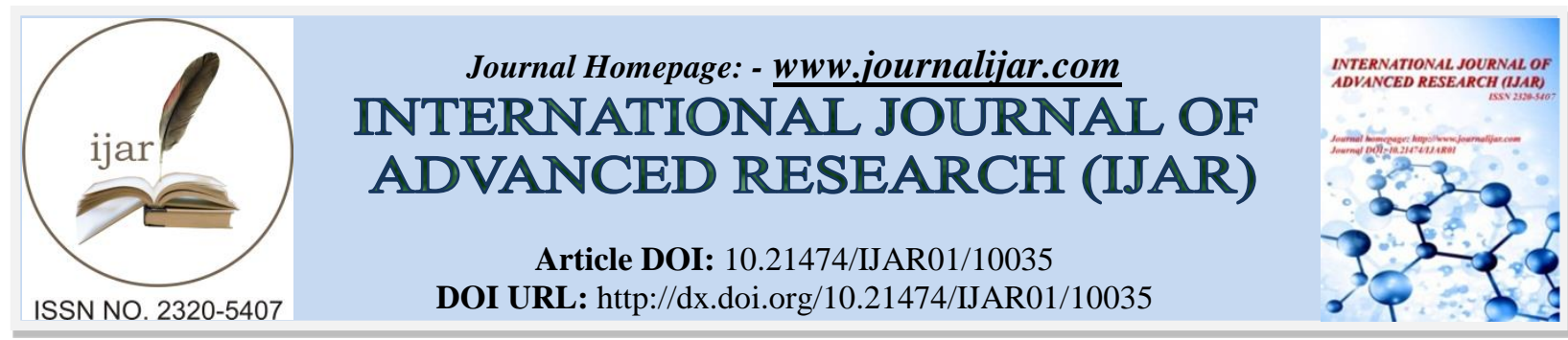

RESEARCH ARTICLE

\title{
MORPHOMETRIC ANALYSIS OF FRONTAL SINUS FOR GENDER DETERMINATION.
}

\section{Dr.Juhi Hussain ${ }^{1}$ and Dr.Mohammad Iqbal ${ }^{2}$, Dr Meenal Airan ${ }^{3}$}

1. Senior Lecturer, Department of Oral Medicine \& Radiology, Rama Dental College, Hopsital \& Research Centre, Kanpur, India.

2. Assistant Professor, Department of Restorative Dental Sciences, Al Baha University, Kingdom of Saudi Arabia. 3. Senior Lecturer, Department of Oral \& Maxillofacial Surgery, Institute of Dental Sciences, Bareilly, India

\section{Manuscript Info}

\section{Manuscript History}

Received: 10 September 2019

Final Accepted: 12 October 2019

Published: November 2019

Key words:-

Frontal sinus, Forensic, Gender Determination.

\section{Abstract}

The field of forensics in dentistry is a growing area of research in the recent times. Dental Radiographs are an important tool when it comes to identification of human remains when there is no other way to discern the identity of a missing person. This study aims to establish the use of Frontal Sinus for Gender Determination by using common Dental Radiographs and thus providing an uncomplicated option to decide sex from skeletal remains.

Methodology: One hundred Digital Caldwell's Radiographs of 50 Males and 50 Females were studied using AutoCAD 2004 software for right, left and total area.

Results: ROC curve analysis,Pearson Correlation and Simple Regression Analysis were used as statistical tools. The mean right, left and total frontal sinus area of males was comparatively higher than females.

Conclusion: It was concluded that AutoCAD method to measure frontal sinus area in radiographs is a reliable method and can be used for determination of gender.

Copy Right, IJAR, 2019,. All rights reserved.

\section{Introduction:-}

The determination of gender of unknown person is of vital importance in forensic investigations, such as anthropologic, medical and dental forensic studies, mainly in cases where only fragments of the skull remain and there is no possibility of identification based on dental arch. ${ }^{[1]}$ Accurate sex prediction of human remains enables a more focussed search of missing person's files.

Sexual dimorphism refers to the difference in size, stature and appearance between males and females. In forensic dentistry many studies have been put forward showing different methods for sex determination.

Among the four major sinuses present in the human skull, namely, the maxillary sinus, frontal, sphenoidal , and ethmoidal, considerable forensic interest in identification has been shown in the frontal sinus.The significance of the sinus in positive identification has been emphasized by anatomists, radiologists and anthropologists who have stated that the frontal sinus of no two persons is alike. ${ }^{[2]}$

Corresponding Author:-Dr.Juhi Hussain.

Address:-Senior Lecturer, Department of Oral Medicine \& Radiology, Rama Dental Collge, Hopsital \& Research Centre, Kanpur, India. 
The frontal sinuses are bilateral anatomical structures/cavities in the frontal bone situated anterior to ethmoid notch. They are not visible at birth, but begin to develop during the second year of life and become radiographically apparent at five years of age. They reach their maximum size by the age of twenty. They are unique in every individual, even in monozygotic twins . This characteristic makes the frontal sinus an important tool in forensic identification .

The co-relation of the morphology of the frontal sinus with gender shows that the frontal sinus is smaller in women, an aspect that points out its characteristic and importance in human identification, as well as the determination of age. $^{[1]}$

The use of frontal sinus for forensic purposes requires a certain amount of precaution as certain environmental factors such as hyperpneumatization due to sport activities disease, trauma, postmortem changes and mainly variations in techniques and radiographs, such as distance, angle and orientation of the cranium, can modify the image of the frontal sinus, distorting its anatomic characteristics and impairing identification of the individual. ${ }^{[1]}$ The primary objectives of the study were: (1) to evaluate the variation in frontal sinus area between male and female subjects and (2) to identify the gender of individuals from frontal sinus area.

\section{Materials and Method:-}

Data was collected from patient with informed consent. 100 Normal Healthy Individuals , 50 Males and 50 Females between the age of 21 to 30 years were included in the study. Patients with Aplasia of Frontal Sinus, Pregnant Females, History of Fractures of Frontal Region, and History of orthodontic treatment or orthognathic surgery, surgery of skull, history or clinical characteristics of endocrine disturbances, nutritional diseases or hereditary facial asymmetries were excluded.

Caldwell's View (PA 15 degree) projects Frontal Sinus above the frontonasal suture, anterior ethmoidal air cells visualized lateral to nasal bone directly below the frontal sinuses.

An $8 * 10$ digital cassette was used in stationary bucky. Radiographs were taken using digital radiography machine at $82 \mathrm{KV}, 10 \mathrm{~mA}$ and $1.00 \mathrm{~s}$ settings. Digital X ray machine (Carestream CS8000 C) was used to take all radiographs.(Fig 1)

After taking the radiograph it was converted to JPEG format. Each X-ray was accessed for frontal sinus area with Auto CAD software 2004. Both right and left and total area of frontal sinus was evaluated and total area was calculated.

\section{Results:-}

The primary outcome measure of the study was frontal sinus area (left and right) and measured in mm ${ }^{2}$. The frontal sinus area (left, right and total) of two groups (male and female) are summarized in Table 1, respectively. The mean right, left and total frontal sinus area of males was comparatively higher than females. Comparing the frontal sinus area of two groups, $t$ test revealed significantly different and higher right frontal sinus area in males than females. Further, the mean right, left and total frontal sinus area of males was found to be $25.4 \%, 24.4 \%$ and $24.9 \%$ higher respectively than females.

The diagnostic accuracy of frontal sinus area to identify gender of the individuals was evaluated using ROC curve analysis and summarized in Table 2. The ROC curve analysis found right, left and total sinus area a significant predictor of gender and among these right frontal sinus area the most which at cutoff value $15.88 \mathrm{~mm}^{2}$, discriminating the cases of two gender with $76.0 \%$ sensitivity and $66.0 \%$ specificity and with $69.1 \%$ positive predictive value and $73.3 \%$ negative predictive value.

To see the difference between left and right frontal sinus area, the comparison between overall (male + female) right and left frontal sinus area was done and summarized in Table 3. The right frontal sinus area ranged from 2.42-44.80 $\mathrm{mm}^{2}$ with mean $( \pm \mathrm{SD}) 17.62 \pm 9.13 \mathrm{~mm}^{2}$ while left frontal sinus area ranged from $2.26-34.46 \mathrm{~mm}^{2}$ with mean $( \pm$ SD) $16.68 \pm 8.46 \mathrm{~mm}^{2}$. The mean right frontal sinus area was sligy higher than the left frontal sinus area. Comparing the mean sinus area of two groups, t test show similar frontal sinus area at left and right i.e. not differed statistically though it was $5.3 \%$ higher at right than left. 
To see the diagnostic accuracy of overall right and left frontal sinus area to identify the sides, the right and left frontal sinus area were subjected to ROC curve analysis and summarized in Table 4 . The ROC curve analysis did not found right and left frontal sinus area the significant predictor of side though showed high sensitivity $62.0 \%$ and moderate specificity $49.0 \%$.

To see the association between overall right and left frontal sinus area, Pearson correlation and simple linear regression analyses were done between right and left frontal sinus area. Pearson correlation analysis show a significant and positive correlation between right and left frontal sinus area $(\mathrm{r}=0.74, \mathrm{p}<0.001)$, indicating a direct association between each other. Further, regression analysis show that the frontal sinus area of one side can be estimated significantly by other side. Regressing the left frontal sinus area against right frontal sinus area, the following best fit regression equation may estimate the left frontal sinus area using right frontal sinus area which accounting $55 \%$ of the total variance.

\section{Discussion:-}

There are considerable variations in the shape and size of the Frontal sinus as encountered during our study and from review of previous studies done in the past. Since studies related to sexual dimorphism are very limited in literature and not many have been attempted on Indian populations, we ventured to take this study to check the reliability and accuracy of Frontal sinus dimensions in gender identification.

Congenital Absence of Frontal Sinus has been excluded in the study. Most previous studies did not exclude this criterion. However we excluded it because such cases are very rare (maximum 4\% as reported by Chetan Belaldavar et al) ${ }^{[3]}$.Patients who have suffered from fractures of the frontal region or those who underwent orthognathic surgery were also excluded on the basis that the bony contour of the frontal sinus may be altered in such cases.

A feature making the Frontal Sinus an ideal structure for identification is its permanency throughout life after the age of 20. Few pathologies have the ability to alter the Frontal Sinus shape, and those that can, do so in a manner readily noticeable to an experienced examiner. Additionally in old age, resorption of the bone walls of the Frontal Sinus has been observed to lead to enlargement of these cavities, potentially affecting its use in positive identification. ${ }^{[4]}$ In this study, the age of subjects ranged from 21 to 30 years for both males and females. This age group was taken into consideration as frontal sinus attains its full maturity at the age of above 20 years. The age above 30 years was not considered as skeletal changes are expected with aging.

In the present study, area of frontal sinus was evaluated on Caldwell's radiograph. Caldwell's view gives a clear view of the frontal and ethmoidal sinuses without loss of definition by superimposition with the petrous ridge of temporal bone, also less magnification is seen in this radiograph as frontal sinus is kept in close approximation with the film receptor. (Paranasal sinus radiographs are often available from a clinical source as they are commonly taken for diagnostic purposes).

In the present study, Auto CAD 2004 software has been used to calculate the area of frontal sinus. Normally, area of regular shapes is calculated by length * breadth formula. This formula cannot be used to calculate area of frontal sinus as it is irregular in shape. The mathematical formula which is aptly used to calculate the area of irregular shapes is one in which a horizontal line joining two farthest most points is drawn, which is equally divided and the line is drawn matching the dividing point and towards the sides of the frontal sinus vertically. After obtaining the length of each line they are added and divided by the length of the horizontal line, hence, area of an irregular shape will be calculated.

AutoCAD software was opted as it is meant to be the most accurate in calculating area of irregular shapes easy, less time consuming and its functions are well adapted to any form of shapes and structures. Studies by Camargo et al ${ }^{[1]}$ , used program SIARCS 3.0 for Windows to calculate length and breadth of frontal sinus . Cristiane Regina Ruiz and Nader Wafae ${ }^{[5]}$ did evaluation of area by using length and breadth formula by software Auto CAD R 14, Chetan Belaldavar et al ${ }^{[3]}$ used Adobe Photoshop CS3 to calculate height and width of frontal sinus, which is mathematically incorrect to calculate area of irregular shapes like that of frontal sinus.

In this study, the mean measurement of right side frontal sinus was greater than the left side in both males and females, which is in contrast to the study done by Camargo et al ${ }^{[1]}$, Jose Marcos Ponde et al ${ }^{[6]}$, Twana Muhammad 
Raoof et al ${ }^{[7]}$ (studies done outside India) but in unison with study by Chetan Belaldavar et al ${ }^{[3]}$ (study on Indian Population) pointing out the fact that this might be a geographical variation of the frontal sinus.

The existence of one side larger than the other is due to the independent development of the frontal sinuses. It is common to find one sinus larger than the other and the larger sinuses may cross the midline and even overlap each other. It was found that the morphology of the frontal sinus of both males and females were different and also assymetrical. Asymmetry for the frontal sinus of both sides is a rule because of the unequal resorption of the dipole during the sinus development.

Statistically significant difference was found in the sinus pattern between males and females in the study ( $\mathrm{p}<0.05$ ). The accuracy of sex determination ranged from $64-88.5 \%$ and the right area was found to be a better predictor of sex than the left area.

Even though males showed greater measurement of frontal sinus than females and also statistically significant difference in the mean value of various parameters between males and females were recorded, the accuracy rate obtained in sex determination in this study was average. Total area of frontal sinuses was larger in males than females as reported by several other authors except the study of Hanson et al on Canadian Eskimo population who reported that the frontal sinus dimensions were larger in females. ${ }^{[8]}$

\section{Conclusion:-}

The Auto CAD method which has been followed for gender determination is a reliable method for gender determination in forensics. Auto CAD method has not been used widely for analysis in earlier studies but is the best suited option so far available. However, further research is required to evaluate the shape and size of the frontal sinus to determine whether it is having $100 \%$ accuracy in gender determination.

There is scope that the frontal sinus evaluation for gender determination should be extended to other age groups (other decades) rather than restricting to third decade (ie, 20 to 30 years) and subject a larger sample size. Further studies might quote more definitive values and provide a strong base for future research. This study added to a definitive trial for the use of morphometric analysis of the frontal sinus for gender determination and to justify its role in forensic sciences.

Fig 1:-Caldwell View Radiograph

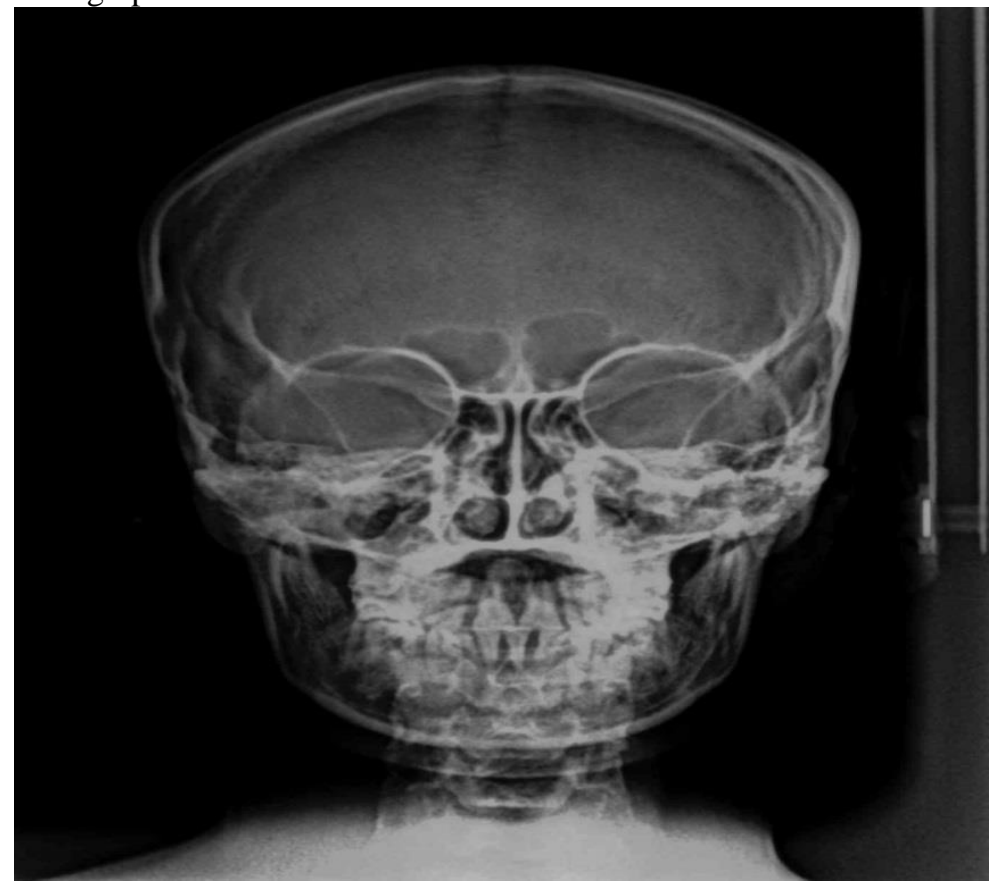

Table 1:-Frontal sinus area (Mean $\pm \mathrm{SD}$ ) of two groups

\begin{tabular}{|c|c|c|c|c|}
\hline Frontal sinus area & Female & Male & t value & p \\
\hline
\end{tabular}




\begin{tabular}{|l|l|l|l|l|}
\hline \multicolumn{1}{|c|}{$\left(\mathbf{m m}^{2}\right)$} & \multicolumn{1}{|c|}{$(\mathbf{n}=\mathbf{5 0})$} & \multicolumn{1}{c|}{$(\mathbf{n = 5 0})$} & \multicolumn{1}{c|}{ value } \\
\hline Right & $15.06 \pm 8.90$ & $20.19 \pm 8.70$ & 2.91 & 0.004 \\
& $(3.25-44.80)$ & $(2.42-42.47)$ & & \\
\hline Left & $14.36 \pm 7.14$ & $19.00 \pm 9.09$ & 2.84 & 0.006 \\
& $(2.26-31.59)$ & $(3.28-34.46)$ & & \\
\hline Total & $29.42 \pm 15.11$ & $39.19 \pm 16.31$ & 3.11 & 0.003 \\
& $(8.09-76.39)$ & $(5.90-71.38)$ & & \\
\hline
\end{tabular}

Numbers in parenthesis indicates the range (min-max)

Table 2:-Diagnostic accuracy of frontal sinus area to identify gender using ROC curve analysis

\begin{tabular}{|l|l|l|l|l|l|l|l|l|l|}
\hline $\begin{array}{l}\text { Frontal } \\
\text { sinus } \\
\text { area }\end{array}$ & $\begin{array}{l}\text { Cutoff } \\
\text { value } \\
\left(\mathbf{m m}^{2}\right)\end{array}$ & $\begin{array}{l}\text { Sensitivity } \\
\mathbf{9 5 \%} \mathbf{C I})\end{array}$ & $\begin{array}{l}\text { Specificity } \\
\mathbf{( 9 5 \%} \mathbf{C I})\end{array}$ & $\mathbf{+ L R}$ & $\mathbf{- L R}$ & $\mathbf{+ P V}$ & $\mathbf{- P V}$ & AUC & p value \\
\hline Right & $>15.88$ & $76.0(61.8-86.9)$ & $66.0(51.2-78.8)$ & 2.24 & 0.36 & 69.1 & 73.3 & 0.690 & $<0.001$ \\
\hline Left & $>21.53$ & $46.0(31.8-60.7)$ & $88.0(75.7-95.4)$ & 3.83 & 0.61 & 79.3 & 62.0 & 0.650 & 0.006 \\
\hline Total & $>35.02$ & $64.0(49.2-77.1)$ & $78.0(64.0-88.5)$ & 2.91 & 0.46 & 74.4 & 68.4 & 0.682 & 0.001 \\
\hline
\end{tabular}

+LR: Positive Likelihood Ratio

-LR: Negative Likelihood Ratio

+ PV: Positive Predictive Value

-PV: Negative Predictive value

Table 3:-Frontal sinus area (Mean \pm SD) of two groups

\begin{tabular}{|l|l|l|l|}
\hline $\begin{array}{l}\text { Right } \\
(\mathbf{n = 1 0 0 )}\end{array}$ & $\begin{array}{l}\text { Left } \\
(\mathbf{n = 1 0 0 )}\end{array}$ & $\begin{array}{l}\text { t value } \\
(\mathbf{D F}=\mathbf{1 9 8})\end{array}$ & $\begin{array}{l}\mathbf{p} \\
\text { value }\end{array}$ \\
\hline $17.62 \pm 9.13$ & $16.68 \pm 8.46$ & 0.76 & 0.451 \\
$(2.42-44.80)$ & $(2.26-34.46)$ & & \\
\hline
\end{tabular}

Numbers in parenthesis indicates the range (min-max)

Table 4:-Diagnostic accuracy of right and left frontal sinus area to identify side using ROC curve analysis

\begin{tabular}{|l|l|l|l|l|l|l|l|l|}
\hline $\begin{array}{l}\text { Cutoff } \\
\text { value } \\
\left(\mathbf{m m}^{\mathbf{2}}\right)\end{array}$ & $\begin{array}{l}\text { Sensitivity } \\
(\mathbf{9 5 \%} \mathbf{C I})\end{array}$ & $\begin{array}{l}\text { Specificity } \\
(\mathbf{9 5 \%} \mathbf{C I})\end{array}$ & +LR & -LR & +PV & -PV & AUC & p value \\
\hline$>14.61$ & $62.0(51.7-71.5)$ & $49.0(38.9-59.2)$ & 1.22 & 0.78 & 54.9 & 56.3 & 0.524 & 0.562 \\
\hline
\end{tabular}

\section{Bibliography:-}

1. Camargo JR, Daruge E, Prado FB, Caria PHF, Alves MC, Silva RF et al. The frontal sinus morphology in radiography of Brazilian Subjects. Braz. J. Morphol. Sci 2007;24(4)239-243.

2. Prabhakaran Nambiar, Murali DK Naidu, Krishnan Subramaniam. Anatomical Variability in Forensic Identification . Clinical Anatomy 1999;12:16-19.

3. Chetan Beladavar, Vijaylakshmi S. Kotrashetti, Seema R Hallikermath, Alka D Kale. Assessment of frontal sinus dimensions to determine sexual dimorphism among Indian adults. Journal of Forensic Dental Sciences. $2014 ; 6(1): 25-30$.

4. Mary Cox, Matthew Malcolm, Scott I Fairgrieve. A New Digital Method for the Objective Comparision of Frontal Sinuses for Identification. J Forensic Sci. July 2009. Vol 54, No 4.

5. Cristiane Regina Ruiz, Nadar Wafae. Anatomo- Radiological and Morphometrical Study of the Frontal Sinus in Humans. Braz. J. Morphol Sci 2004;21(1):53-56.

6. Jose Marcos Ponde, Raimundo Nonato Andreade, Jose Maldonadovia, Patick Metzger, Ana Clara Teles. Anatomical Variations of Frontal Sinus. Int J Morphol. 2008 ; 26 (4):803-808.

7. Twana Muhammad Raoof, Kamal Ahmad Saeed, Kawa A Mahmood.Anatomical Variation of Frontal Sinuses evaluated by CT Scan in relation to age and sex in Sulaimani city. JSMC, 2013(vol 13)No.1.

8. Hanson CL. and Owsley, DW. Frontal Sinus size in Eskimo Populations. Am J Phys. Anthropol. 1980;53 (2) :251-255. 